\title{
Geometria e Desenho Universal para Aprendizagem: uma revisão bibliográfica na Educação Matemática Inclusiva
}

Resumo: Este artigo analisa indícios do Desenho Universal para Aprendizagem na perspectiva da Educação Inclusiva relacionado ao ensino dos conceitos de Geometria. Trata-se de pesquisa qualitativa, do tipo revisão bibliográfica, a partir de busca nas bases SciELO, Biblioteca Digital Brasileira de Teses e Dissertações e Catálogo de Teses e Dissertações da CAPES. Foram selecionadas cinco pesquisas, cujos resultados mostram que para a inclusão não existe um método ou uma prática que atenda aos estudantes com deficiências, mas adaptações para que alcancem aprendizagem. A investigação aponta para a necessidade de maior adesão do DUA para o processo educativo de maneira geral, destacando suas contribuições nas atividades e planejamento no ensino da Matemática para todos os estudantes.

Palavras-chave: Educação Inclusiva. Ensino da Geometria. Desenho Universal para Aprendizagem. Educação Matemática.

\section{Geometry and Universal Design for Learning: a literature review in Inclusive Mathematics Education}

Abstract: This article analyzes evidence of Universal Design for Learning from the perspective of Inclusive Education related to concepts of Geometry. For this, a qualitative research of the methodological principle of bibliographic review was used databases SciELO, Brazilian Digital Library of Theses and Dissertations and the CAPES Theses and Dissertations Catalog. Five researches were selected to analyze the proposed theme, whose results show that for inclusion there is no method or practice that serves students with disabilities, but adaptations so that they reach their goals in the teaching and learning process. The investigation points to the need for greater adherence of the UDL to the educational process in general, detaching its contributions in activities and planning in the teaching of Mathematics for all students.

Keywords: Inclusive Education. Geometry Teaching. Universal Design for Learning. Mathematical Education.

\section{Geometría y Diseño Universal de Aprendizaje: una revisión de la literatura sobre educación matemática inclusiva}

Resumen: Este artículo analiza la evidencia del Diseño Universal de Aprendizaje desde la perspectiva de la Educación Inclusiva asociado con los conceptos de Geometría. Para eso se utilizó una investigación cualitativa del principio metodológico de revisión 
bibliográfica, en bases de datos SciELO, Biblioteca Digital Brasileña de Tesis y Disertaciones y el Catálogo de Tesis y Disertaciones CAPES. Se seleccionaron cinco investigaciones para analizar el tema propuesto, cuyos resultados muestran que para la inclusión no existe un método o práctica que sirva a los estudiantes con discapacidad, sino adaptaciones para que alcancen sus metas en el proceso de enseñanza y aprendizaje. La investigación apunta a la necesidad de una mayor adherencia del DUA al proceso educativo en general, destacando sus aportes en actividades y planificación en la enseñanza de las Matemáticas para todos los estudiantes.

Palabra clave: Educación Inclusiva. Enseñanza de la Geometría. Diseño Universal de Aprendizaje. Educación Matemática.

\section{Introdução}

A Geometria, conforme Dicionário Houaiss da Língua Portuguesa, é a "parte da matemática cujo objeto é o estudo do espaço e das figuras que podem ocupá-lo" (HOUAISS e VILLAR, 2009, p. 966). Com isso, aborda situações que normalmente estão presentes no cotidiano da sociedade e podem ser observadas em diferentes momentos, como em produtos, residências, ruas, natureza, entre outros, como também ser relacionadas a forma e dimensão de objetos e à direção por meio da localização. Diante disso, destaca-se sua importância no cotidiano dos estudantes, bem como a responsabilidade da escola e professores por um trabalho pedagógico que garanta "que os alunos relacionem observações empíricas do mundo real a representações (tabelas, figuras e esquemas) e associem essas representações a uma atividade matemática (conceitos e propriedades), fazendo induções e conjecturas" (BRASIL, 2017, p. 265).

A discussão sobre o ensino e aprendizagem de Geometria é antiga. Lorenzato (1995) defende que "sem estudar Geometria as pessoas não desenvolvem o pensar geométrico ou o raciocínio visual e, sem essas habilidades, elas dificilmente conseguirão resolver as situações de vida que forem geometrizadas" (p. 5), o que pode dificultar o desenvolvimento de habilidades, como a construção, o desenho, as representações, e a percepção de figuras planas e espaciais. Ainda, a nossa experiência docente com Educação Matemática permite verificar que, muitas vezes, o estudante não percebe a Geometria relacionada com os fenômenos físicos existentes no cotidiano. Sobre isso, Góes e Góes (2015, p. 74) destacam que é "na escola que devemos mostrar aos alunos essa interface entre o conhecimento matemático diário e o escolar", podendo o professor desenvolver práticas pedagógicas no ambiente escolar que relacionem a Geometria e até mesmo outros conceitos matemáticos com a vivência do estudante. 
Contudo, o mais comum ainda é perceber que o trabalho pedagógico com a Geometria na Educação Básica é geralmente realizado a partir dos livros didáticos, em ações repetitivas, fazendo uso de memorização das fórmulas algébricas, raramente desenvolvendo o processo de entendimento das situações-problema apresentadas e não as relacionando com problemas práticos do cotidiano. Ainda, "os professores de Matemática se preocupam muito em apresentar os conteúdos de forma que os estudantes memorizem métodos de resolução" (GÓES e GÓES, 2015, p. 71); assim, o estudante pode até desenvolver o conhecimento sobre o assunto, porém normalmente acompanhado da falta de interesse pelo ensino da Geometria.

Segundo a Base Nacional Comum Curricular (BRASIL, 2017, p. 271), "estudar posição e deslocamentos no espaço, formas e relações entre elementos de figuras planas e espaciais pode desenvolver o pensamento geométrico dos alunos", possibilitando o pensamento geométrico, que, por sua vez, pode ser desenvolvido no ambiente escolar com o auxílio da prática pedagógica, desde que o estudante compreenda conceitos e definições dos conteúdos relacionados ao ensino da Geometria, visto que "sem conhecer Geometria a leitura interpretativa do mundo torna-se incompleta, a comunicação das ideias fica reduzida e a visão da Matemática torna-se distorcida" (LOREZANTO, 1995, p. 5). Assim, a Geometria contribui com o processo de desenvolver abstração e generalização pela investigação e exploração das formas geométricas e demais possibilidades disponíveis no cotidiano, vindo a auxiliar no desenvolvimento, compreensão e interpretação de conceitos matemáticos a partir do dia a dia.

Nesse contexto, esta pesquisa busca contribuir com a discussão da Educação Inclusiva, tendo como foco conceitos e conteúdos provenientes da Geometria no cotidiano do estudante, por meio de pesquisa qualitativa, do tipo revisão bibliográfica, considerando o problema: o que revelam as pesquisas com temática sobre práticas de ensino inclusivas em Geometria na Educação Matemática? Para tanto, o estudo busca discutir os seguintes questionamentos, que serviram de diretrizes para a seleção das pesquisas: Quais são as deficiências e/ou transtornos levantados pelos pesquisadores? Quais são as dificuldades específicas de aprendizagem em Matemática? O que os pesquisadores entendem sobre Educação Inclusiva e/ou inclusão? Quais são os levantamentos sobre trabalhos que envolvem o Desenho Universal para Aprendizagem?

Os estudos analisados foram coletados em três bases de dados: Scientific 
Electronic Library Online (SciELO), Biblioteca Digital Brasileira de Teses e Dissertações (BDTD) do Instituto Brasileiro de Informação em Ciência e Tecnologia (IBICT), e Catálogo de Teses e Dissertações da Coordenação de Aperfeiçoamento de Pessoal de Nível Superior (CAPES), em janeiro de 2021, sem corte temporal.

Esta investigação tem a proposta de analisar pesquisas por meio das bases de dados selecionadas, considerando o ensino da Matemática inclusiva com o conteúdo da Geometria na concepção dos conceitos, cálculos de perímetro, área e volume, características das figuras unidimensional, bidimensional e tridimensional que possam contribuir com a aprendizagem de todos os estudantes, por meio da perspectiva do Desenho Universal para Aprendizagem (DUA).

Considerando a importância da aprendizagem da Geometria para todos os estudantes, propostas educativas pelo viés do DUA possibilita que o processo educativo integre a vida cotidiana com os conteúdos científicos e contribua de forma efetiva para todos os envolvidos. Quando se concebe a aprendizagem como direito de todos, torna-se relevante considerar que a realidade das salas de aula contempla a diversidade, devendo a escola e seus agentes viabilizar ações que desenvolvam integralmente os envolvidos, independentemente de possíveis necessidades diferenciadas, buscando incluir todos nos processos de aprendizagem.

Esse artigo é organizado em sete seções, sendo que na próxima é apresentada a compreensão sobre o conceito de deficiência ao longo do tempo. Na seção três é apresentada marcos históricos e legais. Na seção quatro contempla-se a concepção de Desenho Universal para Aprendizagem. Na seção cinco apresenta-se os principais resultados e contribuições para o avanço do tema na área. Na sequência, são destacados os resultados e análises das pesquisas selecionadas e, por fim, apresenta-se as considerações finais e levantamentos de como esse estudo pode contribuir com a temática.

\section{A compreensão sobre pessoas com deficiência ao longo do tempo}

Ao longo do tempo, diversas expressões foram utilizadas para caracterizar as pessoas com deficiências. Tais alterações na terminologia ocorreram devido às mudanças no processo de aceitação da sociedade e algumas delas, atualmente, podem causar desconforto, por remeter à existência de um ser ideal. Uma dessas expressões é pessoa 
com defeito, indicada por Vygotsky em sua obra Fundamentos da defectologia, escrita nas primeiras décadas do século XX. Na década de 1920 era utilizado o termo incapacitado para remeter à pessoa que não era capaz. No entanto, atualmente há a compreensão de que as pessoas podem estar incapacitadas momentaneamente em função das barreiras que precisam ser extintas. Entende-se por barreira o apresentado na Lei $\mathrm{n}^{\circ}$ 13.146/2015, conhecida como Lei Brasileira de Inclusão da Pessoa com Deficiência ou Estatuto da Pessoa com Deficiência:

\begin{abstract}
IV - barreiras: qualquer entrave, obstáculo, atitude ou comportamento que limite ou impeça a participação social da pessoa, bem como o gozo, a fruição e o exercício de seus direitos à acessibilidade, à liberdade de movimento e de expressão, à comunicação, ao acesso à informação, à compreensão, à circulação com segurança, entre outros, classificadas em: a) barreiras urbanísticas: as existentes nas vias e nos espaços públicos e privados abertos ao público ou de uso coletivo; b) barreiras arquitetônicas: as existentes nos edifícios públicos e privados; c) barreiras nos transportes: as existentes nos sistemas e meios de transportes; d) barreiras nas comunicações e na informação: qualquer entrave, obstáculo, atitude ou comportamento que dificulte ou impossibilite a expressão ou o recebimento de mensagens e de informações por intermédio de sistemas de comunicação e de tecnologia da informação; e) barreiras atitudinais: atitudes ou comportamentos que impeçam ou prejudiquem a participação social da pessoa com deficiência em igualdade de condições e oportunidades com as demais pessoas; f) barreiras tecnológicas: as que dificultam ou impedem o acesso da pessoa com deficiência às tecnologias. (BRASIL, 2015, Art. $3^{\circ}$ ).
\end{abstract}

Na década de 1960, os documentos e estudos passaram a utilizar o termo deficiente, que atualmente apresenta a mesma sensação da expressão empregada por Vygotsky em seus estudos. No final da década de 1980, a terminologia usada era pessoa portadora de deficiência, abolida em poucos anos, uma vez que se refere a algo que a pessoa leva consigo, podendo até mesmo transmitir a outras pessoas. Já na década de 1990, a expressão pessoas com necessidades especiais foi difundida, sendo relativa ao indivíduo que necessita de ambientes, recursos e artefatos adaptados, ou seja, indica que as barreiras devem ser "quebradas" quando há necessidade, em vez de se pensar em projetos que não tenham barreiras.

Atualmente, desde a Convenção Internacional sobre os Direitos de Pessoas com Deficiência da Organização das Nações Unidas (ONU) em Nova Iorque, no ano de 2007, promulgada pelo Decreto $n^{\circ}$ 6.949/2009 (BRASIL, 2009), o termo utilizado é pessoa com deficiência, tendo o seguinte significado no documento: 
Pessoas com deficiência são aquelas que têm impedimentos de longo prazo de natureza física, mental, intelectual ou sensorial, os quais, em interação com diversas barreiras, podem obstruir sua participação plena e efetiva na sociedade em igualdades de condições com as demais pessoas (BRASIL, 2009, Art. 1).

Tal terminologia apresenta o empoderamento da pessoa com deficiência, no sentido de ter controle de sua vida, pois o que a impede de usufruir e viver na sociedade atual são as barreiras existentes.

Destaca-se que as crianças com alguma deficiência nascidas na Antiguidade Clássica eram abandonadas; na Roma Antiga, eram transformadas em empregadas de luxo e prostituição; no século IV, as pessoas com deficiência eram internadas, porém sem tratamento médico especializado; já entre os séculos XI e XII, eram consideradas castigadas por Deus; entre os séculos XVII e XVIII, aquelas com deficiência visual começaram a ser consideradas de forma diferenciada na educação escolar, com o início do Sistema Braille; no século XIX, com a Revolução Industrial, surgiram ideias de que essas pessoas poderiam contribuir com sua mão de obra em determinados setores; no século XX, após a Segunda Guerra Mundial, teve início a criação de programas de reabilitação para pessoas com deficiência congênita ou adquirida (PARANÁ, 2018).

Esse processo de reconhecimento dos direitos das pessoas com deficiência tem respaldo no esporte, tendo acontecido em 1960 o primeiro jogo paraolímpico. A participação social de pessoas com deficiência foi marcada durante anos por preconceitos e exclusão. A partir dos anos 1990, foram criadas leis específicas para elas, que contribuíram para a igualdade de condições e oportunidade (PARANÁ, 2018), assegurando os direitos sociais com equidade. No Programa Nacional de Direitos Humanos, criado em 2002, Valente (2015) comenta que "Direitos Humanos são aqueles comuns a todos os seres Humanos em qualquer lugar no nosso planeta, pois são os direitos que cada ser humano tem sem distinção de etnia, nacionalidade, gênero, classe social, grau de instrução, religião, opinião política, orientação social” (p. 175).

As ações promovidas pelas entidades contra o preconceito das pessoas com deficiência ocasionaram transformações em muitos espaços sociais. Com isso, os governos precisaram alterar leis específicas, que deram suporte para esse público alcançar sua inclusão social e escolar. Com o mesmo objetivo, inúmeras conferências debateram os direitos humanos, não apoiando a discriminação, preconceito e segregação ainda 
existentes. No entanto, no ambiente escolar, as discussões sobre a Educação Inclusiva ainda geram dúvidas, uma vez que as instituições de ensino foram criadas e organizadas a partir do passado para receber e atender a estudantes que não apresentassem deficiências. Talvez pelo fato de as disciplinas dos cursos de licenciatura não contemplarem, de maneira geral, tais discussões, isso impossibilitaria atender a todos os estudantes com equidade na Educação Básica, onde a maioria dos licenciados atua.

Nesse viés, são necessárias a discussão da temática e a compreensão do percurso da legislação e da evolução do termo Educação Inclusiva, que surgiu no Brasil entre os anos 1980 e 1990, sendo efetivado por meio da Lei de Diretrizes e Bases da Educação Nacional (BRASIL, 1996). O referido documento possibilitou perspectivas diferenciadas na educação especial, motivadas pela Declaração de Salamanca de 1994 (BRASIL, 1994), que indica que o estudante com deficiência pode ser matriculado nas escolas regulares, garantindo, assim, que o "atendimento especializado deve estar disponível em todos os níveis de ensino, de preferência na rede regular, desde a educação infantil até a universidade" (MANTOAN, 2003, p. 23).

No ambiente escolar, devem ser acolhidas "todas as pessoas no sistema de ensino, independentemente de cor, classe social, e condições físicas e psicológicas" (MORAES, 2017, p. 6). Diante disso, começaram manifestações e movimentos de alguns pais de estudantes sem deficiência que não admitiam a inclusão, pois tinham a ideia de que as escolas iriam baixar ou piorar sua qualidade de ensino se recebessem estudantes com algum tipo de deficiência (MANTOAN, 2003). Nesse cenário, a sociedade por décadas tem mostrado algum tipo de discriminação e segregação, que prega o preconceito de pessoa com deficiência. Com a necessidade de combater os preconceitos, a sociedade precisa evoluir nas concepções de aceitação, como comenta Mantoan (2003, p. 14): “Se o que pretendemos é que a escola seja inclusiva, é urgente que seus planos se redefinam para uma educação voltada para a cidadania global, plena, livre de preconceitos e que reconheça e valoriza suas diferenças".

A escola, como parte integrante da sociedade, tem um papel relevante no processo de inclusão; sendo assim, o debate educacional voltado à igualdade de direitos tem se intensificado, conforme é possível verificar na próxima seção, que apresenta as conquistas no campo educacional para as pessoas com deficiência a partir da legislação. 


\section{Marcos históricos e legais}

No Brasil, o atendimento das pessoas com deficiência nas instituições especializadas começou timidamente, com mudanças estruturais e culturais em busca da especialização de atendimento. Desde então, foram criadas leis, diretrizes, programas, constituição, estatutos, conferências, planos e decretos referenciando os direitos desse público, conforme mostra o Quadro 1.

Quadro 1: Processo de atendimentos e leis no Brasil

\begin{tabular}{|c|c|}
\hline Período & Descrição \\
\hline 1854 & Atendimento de deficiência visual — Imperial Instituto dos Meninos Cegos \\
\hline 1857 & Atendimento de deficiência auditiva — Instituto Benjamin Constant \\
\hline 1926 & Atendimento de deficiência metal — Instituto Pestalozzi \\
\hline 1945 & $\begin{array}{l}\text { Criado primeiro atendimento educacional de superdotação — Sociedade } \\
\text { Pestalozzi }\end{array}$ \\
\hline 1954 & Fundada primeira Associação de Pais e Amigos dos Excepcionais (Apae) \\
\hline 1961 & $\begin{array}{l}\text { Lei no 4.024/1961 (Lei de Diretrizes e Bases da Educação Nacional), direito dos } \\
\text { "excepcionais" no sistema geral de ensino }\end{array}$ \\
\hline 1971 & $\begin{array}{l}\text { Alteração da Lei de Diretrizes e Bases da Educação Nacional de } 1961 \text { pela Lei no } \\
\text { 5.692/1971, encaminhamento de pessoas com deficiência para as classes e } \\
\text { escolas especiais }\end{array}$ \\
\hline 1973 & $\begin{array}{l}\text { Criado pelo Ministério da Educação (MEC) o Centro Nacional de Educação } \\
\text { Especial (Cenesp) }\end{array}$ \\
\hline 1988 & Constituição Federal \\
\hline 1990 & Lei no 8.069/1990 (Estatuto da Criança e do Adolescente) \\
\hline 1994 & Política Nacional de Educação Especial \\
\hline 1996 & Lei nº 9.394/1996 (Lei de Diretrizes e Bases da Educação Nacional) \\
\hline 2001 & Resolução CNE/CEB nº 2/2001 - educação especial na Educação Básica \\
\hline 2001 & Lei no $10.172 / 2001$ — Plano Nacional de Educação \\
\hline 2001 & Decreto n o 3.956/2001 — Convenção da Guatemala (1999) \\
\hline 2002 & Resolução CNE/CP nº 1/2002 - perspectiva na Educação Inclusiva \\
\hline 2003 & Programa Educação Inclusiva criado pelo MEC \\
\hline 2004 & $\begin{array}{l}\text { Decreto }^{\circ} \text { 5.296/2004, regulamentou as Leis } n^{\circ} 10.048 / 2000 \text { e } \mathrm{n}^{\circ} 10.098 / 2000 \text {, } \\
\text { impulsionando a inclusão social e educacional (Programa Brasil Acessível) }\end{array}$ \\
\hline 2005 & $\begin{array}{l}\text { Decreto } n^{\circ} 5.626 / 2005 \text { regulamentou a Lei } n^{\circ} 10.436 / 2002 \text {, inclusão de estudantes } \\
\text { surdos pelo sistema de Língua Brasileira de Sinais (Libras) }\end{array}$ \\
\hline 2006 & Convenção sobre os direitos das pessoas com deficiências aprovado pela ONU \\
\hline 2007 & Decreto $n^{\circ}$ 6.094/2007, compromisso Todos pela Educação \\
\hline
\end{tabular}




\begin{tabular}{|c|c|}
\hline 2008 & Política Nacional de Educação na Perspectiva da Educação Inclusiva \\
\hline 2009 & Resolução CNE/CP n ${ }^{\circ}$ 04/2009 — atendimento educacional especializado \\
\hline 2011 & Decreto $\mathrm{n}^{\circ} 7.611 / 2011$ - implantação do atendimento educacional especializado \\
\hline 2014 & $\begin{array}{l}\text { Decreto } n^{\circ} 8.368 / 2014 \text { instituiu a Política Nacional de Proteção dos Direitos de } \\
\text { Pessoas com Transtorno do Espectro Autista }\end{array}$ \\
\hline 2015 & $\begin{array}{l}\text { Lei } n^{\circ} 13.146 / 2015 \text { instituiu a Lei Brasileira de Inclusão da Pessoa com } \\
\text { Deficiência }\end{array}$ \\
\hline
\end{tabular}

Fonte: Elaborado pelos Autores (2021)

Apesar de iniciativas isoladas no cenário educacional, foi a partir da década de 1950 (Quadro 1) que os estudantes com deficiência tiveram conquistas significativas nos processos de ensino e de aprendizagem. Uma dessas mudanças foi a criação das escolas especiais ou classes especiais de ensino, possibilitando o atendimento especializado, quando "pela integração escolar, o aluno tem acesso às escolas por meio de um leque de possibilidades educacionais, que vai da inserção às salas de aula do ensino regular ao ensino em escolas especiais" (MANTOAN, 2003, p. 15). Esse movimento ocorreu paralelamente às discussões dos direitos humanos, sobretudo devido ao aumento de pessoas, ex-combatentes, com deficiência ocasionado pela Segunda Guerra Mundial.

No final do século XX, algumas entidades lutaram a fim de organizar estratégias de ações, como palestras, propagandas, vídeos de orientação e outras, sobre as práticas de segregação das pessoas deficientes nos mais diversos ambientes, entre eles, o escolar. Para consolidar o processo das ações planejadas pelas entidades, a Declaração de Salamanca (1994) defendeu a busca de melhorias para as pessoas com deficiência no sistema de ensino, diminuindo gradativamente adversidades referentes à exclusão. No mesmo sentido, a Política Nacional de Educação Especial na Perspectiva da Educação Inclusiva expressa que "a partir do processo de democratização da educação se evidencia o paradoxo inclusão/exclusão, quando os sistemas de ensino se universalizam o acesso, mas continuam excluindo indivíduos e grupos considerados fora dos padrões homogeneizadores da escola" (BRASIL, 2008, p. 6).

$\mathrm{Na}$ atualidade, os estudantes com deficiência - visual, auditiva, física, intelectual, psicossocial ou múltipla - são considerados um desafio ao serem inseridos na Educação Básica regular, pois ainda existe certa resistência em aceitá-los por alguns educadores e pela própria escola (MANTOAN, 2003). Isso acontece devido a possíveis dificuldades que alguns educadores sentem em lidar com estudantes que possuem 
deficiência, por não encontrarem recursos apropriados que possam ser adaptados ao seu processo de ensino e aprendizagem, como também por não apresentarem formação adequada para lidar com esse estudante. A despeito disso, é preciso lembrar que a Lei $\mathrm{n}^{\circ}$ 13.146/2015 estabelece que "é dever do Estado, da família, da comunidade escolar e da sociedade assegurar educação de qualidade à pessoa com deficiência, colocando-a a salvo de toda violência, negligência e discriminação" (BRASIL, 2015, p. 6).

Verifica-se a existência de inúmeras ações indicadas nos documentos que devem ser colocados em prática e que, em algum contexto, podem ser capazes de contribuir em situações cotidianas da pessoa com deficiência, porém, essas ações muitas vezes ficam apenas no documento, não sendo integradas e discutidas nos cursos de formação inicial e continuada, ou quando são, acontecem de forma isolada que não alcançam a maioria dos profissionais. Não que isso isente o professor de buscar alternativas para superar as dificuldades no trabalho cotidiano com a diversidade, mas destaca-se a importância de se expandir discussões sobre esse assunto emergente que é a inclusão.

$\mathrm{Na}$ perspectiva do atendimento e respeito aos direitos das pessoas de se locomover, trabalhar e estudar, surgiram outras possibilidades na sociedade e concepções como o Desenho Universal, com o intuito de possibilitar o acesso de todas as pessoas aos espaços arquitetônicos e à utilização de artefatos. Para Gabrilli (2007, p. 10), “o Desenho Universal não é uma tecnologia direcionada apenas aos que dele necessitam; é desenhado para todas as pessoas". Ainda, sendo a escola parte integrante da sociedade, os processos educacionais não podem ficar aquém de tais concepções; tendo a necessidade de adaptações nos materiais e metodologias educativas, a fim de garantir que todos os estudantes tenham os mesmos direitos de aprender, tem-se a perspectiva do Desenho Universal para Aprendizagem, não deixando de lado os princípios do Desenho Universal, sobretudo na concepção de recursos e ambientes educacionais.

Mesmo com o avanço da legislação que procura garantir o aprendizado a todos os estudantes, percebemos, em nossa experiência profissional, que as práticas de ensino muitas vezes não consideram os estudantes com deficiência, padronizando o processo a partir de uma única análise, provavelmente pela falta de debate na formação inicial dos professores e/ou discussões no ambiente escolar que não se aprofundam, em que não há apresentação de diretrizes para alcançar a inclusão com materiais e metodologias que 
possibilitem ações educativas a todos os estudantes.

\section{Concepção de Desenho Universal para Aprendizagem}

O Desenho Universal - do inglês universal design — foi desenvolvido na Universidade da Carolina do Norte, nos Estados Unidos, em 1987, pelo arquiteto Ronald Mace e colaboradores, para planejar construção civil e produtos acessíveis para todos. Gabrilli (2007, p. 10) comenta que o Desenho Universal "é o processo de criar os produtos que são acessíveis para todas as pessoas, independentemente de suas características pessoais, idade ou habilidades". A Lei $\mathrm{n}^{\mathrm{o}}$ 13.146/2015, em seu art. 55, apresenta o Desenho Universal como

a concepção e a implantação de projetos que tratem do meio físico, de transporte, de informação e comunicação, inclusive de sistemas e tecnologias da informação e comunicação, e de outros serviços, equipamentos e instalações abertos ao público, de uso público ou privado de uso coletivo, tanto na zona urbana como na rural, devem atender aos princípios do Desenho Universal, tendo como referência as normas de acessibilidade (BRASIL, 2015, Art. 55)

Assim, foram estabelecidos sete princípios aplicados mundialmente para qualquer esboço criado com o intuito de ter acessibilidade para todos (GABRILLI, 2007), conforme ilustra o Quadro 2.

Quadro 2: Sete princípios para acessibilidade a todos

\begin{tabular}{|l|l|}
\hline \multicolumn{1}{|c|}{ Uso } & \multicolumn{1}{c|}{ Descrição } \\
\hline Igualitário & $\begin{array}{l}\text { Garante que espaços e produtos sejam utilizados por pessoas } \\
\text { com diferentes deficiências, criados igualmente para todos. }\end{array}$ \\
\hline Adaptável ou flexível & $\begin{array}{l}\text { O desenho dos produtos ou espaços deve ser adaptável para } \\
\text { atender a todos, para qualquer uso. }\end{array}$ \\
\hline Óbvio ou intuitivo & $\begin{array}{l}\text { Qualquer produto ou espaço deve ter facilidade de assimilação } \\
\text { e compreensão do indivíduo, independentemente de sua } \\
\text { experiência, habilidade, conhecimento. }\end{array}$ \\
\hline $\begin{array}{l}\text { Conhecido ou informação } \\
\text { de fácil percepção }\end{array}$ & $\begin{array}{l}\text { A comunicação e a informação devem atender ao público } \\
\text { receptor, em diferentes aplicações, como o Sistema Braille, } \\
\text { símbolos, entre outros. }\end{array}$ \\
\hline Seguro ou tolerante ao erro & $\begin{array}{l}\text { Os produtos e ambientes devem ser idealizados para diminuir os } \\
\text { riscos e consequência de acidentes. }\end{array}$ \\
\hline $\begin{array}{l}\text { Sem esforço ou baixo } \\
\text { esforço físico }\end{array}$ & $\begin{array}{l}\text { Proporciona conforto na utilização de produtos e ambientes, } \\
\text { incluindo a minimização de ações repetitivas. }\end{array}$ \\
\hline Abrangente & $\begin{array}{l}\text { Estabelece dimensões apropriadas para acessar, alcançar, } \\
\text { manipular e utilizar produtos e ambientes. }\end{array}$ \\
\hline
\end{tabular}

Fonte: Gabrilli (2007), com adaptação pelos autores (2021) 
Assim, a criação de materiais manipulativos no ambiente escolar para superar os obstáculos de aprendizagem de cada estudante, muitas vezes, tem como concepção-base os sete princípios do Desenho Universal.

Com a ideia de acessibilidade para todos, o Desenho Universal proporcionou repensar os objetos físicos e espaços. A partir desse processo, foi elaborado o conceito do Desenho Universal para Aprendizagem, o qual possibilita o trabalho pedagógico a partir de diretrizes metodológicas que consideram todos os envolvidos no processo. Esse conceito foi elaborado por David Rose, Anne Mayer e por todos que trabalham no Center for Applie Special Technology (CAST), que atualmente ampliou seu campo para o planejamento do currículo na pesquisa educacional fundamentada no Desenho Universal para Aprendizagem, no desenvolvimento de software, legislações estaduais e nacionais e no preparo dos educadores (CAST, 2021).

Para desenvolver o Desenho Universal para Aprendizagem, precisa ser observados três princípios das diretrizes metodológicas (CAST, 2021): (i) engajamento, "por que" da aprendizagem, otimizando a aprendizagem com interesse, persistência e autorregulação, com vistas à motivação; (ii) representação, “o que” da aprendizagem, facilitando a aprendizagem na percepção, linguagem e compreensão, com o objetivo de construir conhecimentos; (iii) ação e expressão, "como" da aprendizagem, envolvendo ação física, expressão e comunicação e funções executivas que direcionam a aprendizagem aos seus objetivos (Figura 1), pois o Desenho Universal para Aprendizagem possibilita uma estrutura proporcionando uma otimização na aprendizagem para todos com bases nas percepções cientificas de como as pessoas aprendem (CAST, 2021).

A Figura 1 mostra que cada um dos princípios é subdividido em três diretrizes metodológicas, que indicam possibilidades práticas diferenciadas no ambiente escolar, as quais oferecem acessibilidade e aprendizagem a todos os estudantes. Cada diretriz, em cada princípio, busca indicar formas de acesso, construção e internalização da apresentação. Ao garantir as diretrizes, isso resulta em estudantes dedicados e motivados no princípio de engajamento; estudantes engenhosos e experientes no princípio de representação; e estudantes estratégicos e direcionados a metas no princípio de ação de expressão. Assim, busca-se uma educação em que os estudantes construam sua autonomia 
e conhecimento, de forma que possam estar associados à sua realidade (CAST, 2021). Sendo assim, observa que as diretrizes metodológicas podem contribuir para as propostas desenvolvidas pelos professores no ensino da Matemática no conteúdo de Geometria em diferentes práticas no ambiente escolar para todos os estudantes com/sem deficiências.

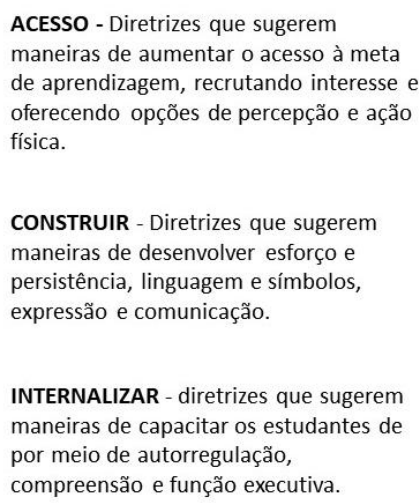

CONSTRUIR - Diretrizes que sugerem maneiras de desenvolver esforço e persistência, linguagem e símbolos, expressão e comunicação.

INTERNALIZAR - diretrizes que sugerem maneiras de capacitar os estudantes de por meio de autorregulação, compreensão e função executiva.

Objetivo: estudantes especialistas que são...

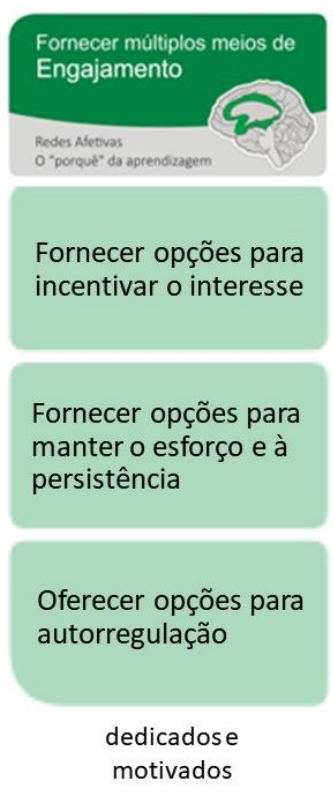

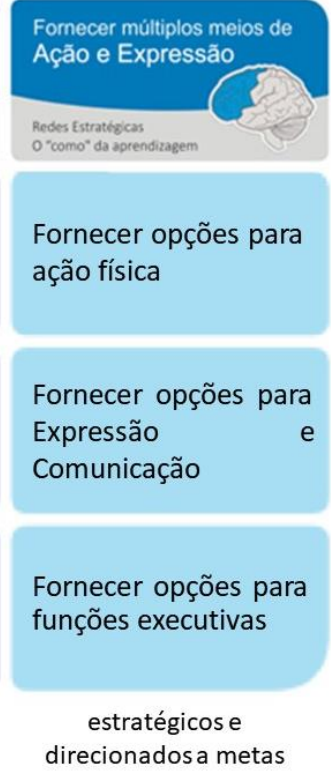

Figura 1: Princípios e diretrizes do Desenho Universal para Aprendizagem

(CAST, 2021, adaptado e traduzido pelos autores, 2021)

\section{Principais resultados e contribuições para o avanço do tema na área}

Para responder à questão de pesquisa — o que revelam as pesquisas com temática sobre práticas de ensino inclusivas em Geometria na Educação Matemática? —, questionamentos auxiliares foram definidos, a saber: Quais são as deficiências e/ou transtornos levantados pelos pesquisadores? Quais são as dificuldades específicas de aprendizagem em Matemática? O que os pesquisadores entendem sobre Educação Inclusiva e/ou inclusão? Quais são os levantamentos sobre trabalhos que envolvem o Desenho Universal para Aprendizagem? Com base neles, foi desenvolvida uma pesquisa qualitativa de cunho bibliográfico.

Segundo Trevisol Neto (2017, p. 39), um levantamento bibliográfico é realizado “a partir de material já publicado que passou por tratamento analítico, assim, o propósito dessas publicações é que sejam lidas e consultadas por grupos específicos". Dessa forma, buscaram-se pesquisas desenvolvidas nos bancos de dados, com a Geometria relacionada com a Educação Matemática Inclusiva.

O levantamento dos documentos deu-se em janeiro de 2021, não utilizando o corte 
temporal, nas seguintes bases de dados: SciELO, Catálogo de Teses e Dissertações da CAPES e BDTD. Na primeira base constam artigos e nas demais, trabalhos associados a teses e dissertações. Para a seleção das pesquisas, foram utilizados os seguintes termos: Inclusão, Educação Inclusiva, Ensino, Geometria, Ensino Fundamental, Ensino Médio, Desenho, Geométrico e Desenho Universal para Aprendizagem, assim como combinações com os operadores booleanos or e and, utiliza-se esses operadores como estratégias em buscar pesquisa dessa temática, por meio dos títulos e resumos, sendo que o and, busca um encontro entre os termos e o or possibilita a união entre todos os termos. A partir disso, foram realizadas cinco buscas em cada uma das bases.

Para a primeira busca, observou-se que o entendimento de uma abordagem com recursos didáticos aplicados a todas as pessoas pode ocorrer por meio do Desenho Universal para Aprendizagem. O Catálogo de Teses e Dissertações da CAPES retornou quatro pesquisas; a SciELO, duas pesquisas; e a BDTD, cinco pesquisas. Dessas 11 pesquisas, nenhuma abordava o ensino da Matemática ou da Geometria, tendo sido descartadas para a análise.

Na segunda busca, utilizou-se a combinação: (Inclusão or "Educação Inclusiva" and Ensino and Geometria and ("Ensino Fundamental" OR "Ensino Médio"). Com isso, buscou-se pesquisas que contemplassem temas como inclusão ou Educação Inclusiva e ensino, Geometria, tanto no Ensino Fundamental quanto no Médio. Esta busca teve retorno de 13 pesquisas na base de dados do Catálogo de Teses e Dissertações, todas dissertações; a plataforma SciELO retornou duas pesquisas; e, na BDTD, obtive-se 16 pesquisas, considerando 15 dissertações e uma tese. Assim, desta combinação resultou 31 pesquisas a ser analisadas pelos demais critérios de inclusão e exclusão.

A terceira busca, com a combinação (Inclusão OR "Educação Inclusiva”) and Desenho and Geométrico and ("Ensino Fundamental" or "Ensino Médio"), teve o intuito de encontrar pesquisas que contemplassem os temas inclusão e Educação Inclusiva associados aos temas desenho e geométrico no Ensino Fundamental e Médio. Tanto na base de dados da BDTD quanto no Catálogo de Teses e Dissertações, obteve-se o retorno de uma pesquisa. Já na base de dados da SciELO, nenhum trabalho retornou. Assim, duas pesquisas foram selecionadas para aplicar os demais critérios de inclusão e exclusão.

A quarta busca nas bases de dados procurou por pesquisas que abordaram os temas 
desenho e geométrico ou ensino e Geometria com Desenho Universal para Aprendizagem. Para isso, a combinação utilizada foi ((Desenho and Geométrico) or (Ensino AND Geometria)) and "Desenho Universal para Aprendizagem". A BDTD e a SciELO não retornaram pesquisas, porém o Catálogo de Teses e Dissertações teve 68 resultados; analisadas as pesquisas, não se constataram trabalhos que envolvessem o Desenho Universal para Aprendizagem.

Por fim, na quinta busca, a combinação "Desenho Universal para Aprendizagem" and (Inclusão or "Educação Inclusiva") teve o objetivo de identificar as pesquisas que focavam o Desenho Universal para Aprendizagem e a inclusão ou Educação Inclusiva. Houve o retorno de quatro trabalhos na BDTD, dois trabalhos na SciELO, e uma pesquisa no Catálogo de Teses e Dissertações da CAPES. No entanto, verificou-se que as sete pesquisas não estavam relacionadas à Educação Matemática e/ou ao ensino da Geometria, tendo sido excluídas por não contemplar o tema proposto neste artigo. A Tabela 1 apresenta o número de pesquisas retornadas e selecionadas em cada base de dados.

Tabela 1: Pesquisas retornadas e selecionadas

\begin{tabular}{l|c|c|c|c|c|c}
\hline \multirow{2}{*}{ Combinações dos termos } & \multicolumn{2}{c|}{ CAPES } & \multicolumn{2}{c|}{ BDTD } & \multicolumn{2}{c}{ SciELO } \\
\cline { 2 - 8 } & PR & PS & PR & OS & PR & PS \\
\hline $\begin{array}{l}\text { "Desenho Universal para Aprendizagem" } \\
\text { (Inclusão or "Educação Inclusiva") and Ensino and } \\
\text { Geometria and ("Ensino Fundamental" or "Ensino Médio") }\end{array}$ & 13 & 13 & 16 & 16 & 2 & 2 \\
\hline $\begin{array}{l}\text { (Inclusão or "Educação Inclusiva") and Desenho and } \\
\text { Geométrico and ("Ensino Fundamental" or "Ensino } \\
\text { Médio") }\end{array}$ & 1 & 1 & 1 & 1 & 0 & 0 \\
\hline $\begin{array}{l}\text { ((Desenho and Geométrico) or (Ensino e Geometria)) and } \\
\text { "Desenho Universal para Aprendizagem" }\end{array}$ & 68 & 0 & 0 & 0 & 0 & 0 \\
\hline $\begin{array}{l}\text { "Desenho Universal para Aprendizagem" and (Inclusão or } \\
\text { "Educação Inclusiva") }\end{array}$ & 1 & 0 & 4 & 0 & 2 & 0 \\
\hline
\end{tabular}

Total de pesquisas retornadas 119

Total de pesquisas selecionadas 33

Notas: PR - pesquisas retornadas. PS — pesquisas selecionadas.

Fonte: Elaborado pelos Autores (2021)

Das 119 pesquisas retornadas nas buscas, 33 foram selecionadas, conforme a Tabela 1, para aplicar os demais critérios de inclusão e exclusão. No primeiro critério de inclusão/exclusão, foi verificado se havia pesquisas retornadas por mais de uma combinação ou base de dados, constatando-se a repetição e versões incompletas de dez 
pesquisas, as quais foram excluídas, permanecendo 23 pesquisas analisadas pelo próximo critério.

No segundo critério, foi realizada a leitura dos títulos com a finalidade de verificar se estavam em consonância com o tema pesquisado. Nesta análise, foram excluídas dez pesquisas que não traziam em seus títulos a informação de serem sobre Educação Matemática. Muitas delas retornaram das bases pelo fato de contemplarem em seu título ou resumo os termos indicados nas buscas, mas não se relacionavam ao tema proposto. Assim, com este critério permaneceram 13 pesquisas.

O terceiro critério consistiu na leitura dos resumos para análise e discussões para responder às questões preestabelecidas. Com isso, foram excluídas oito pesquisas, pois se percebeu que eram estudos teóricos e não práticas relacionadas ao contexto educacional, bem como pesquisas com ênfase em outros conteúdos matemáticos e não à Geometria. Dessa forma, cinco pesquisas permaneceram para análise, descritas a seguir.

Arnoldo Junior (2010) desenvolveu a pesquisa Estudo do desenvolvimento do pensamento geométrico por alunos surdos por meio do multiplano do Ensino Fundamental, com o objetivo de contribuir na aprendizagem dos estudantes em conteúdos matemáticos do ensino da Geometria. O pesquisador observou estudantes surdos, estudando num primeiro momento as figuras geométricas, modeladas com recortes com cartolinas. Na sequência, utilizou o recurso do Multiplano® para construção de algumas figuras, como quadrado, retângulo, trapézio, entre outras. A partir disso, foram abordados o nome, o número de lados e a percepção das figuras, reta (paralela, concorrente e perpendicular), ponto, ângulo (oblíquo e reto) e, por fim, o conceito de área.

O ensino da Geometria para alunos com deficiência visual é o título da pesquisa de Silva (2013), que investigou a forma como os materiais desenvolvidos e construídos pelo pesquisador contribuíram e auxiliaram um estudante com deficiência visual na compreensão das figuras geométricas planas e espaciais. No primeiro momento da pesquisa, o objetivo foi verificar como o estudante reconhecia as propriedades das figuras geométricas, como as figuras planas: quadrado, retângulo e triângulo equilátero, isósceles e escaleno. Após isso, utilizou materiais desenvolvidos com etileno vinil acetato (EVA) para figuras planas e com acrílico para sólidos geométricos, bem como alguns materiais com compensado, com o qual o estudante pôde construir os seguintes sólidos 
geométricos: cubo, paralelepípedo, prisma triangular com base triangular equilátera, prisma triangular com base triangular isósceles e prisma triangular com base triangular escalena. Ficou evidente a lacuna preenchida para o estudante, como diferenças básicas entre pirâmides e prismas com bases triangulares ou, ainda, entre quadrados e cubos, bem como suas propriedades.

Visando a analisar questões apresentadas no exame de seleção do Colégio Militar de Fortaleza, especificamente sobre figuras geométricas planas, medidas de comprimento, de superfície e de volume, Silveira (2017) desenvolveu a pesquisa denominada Comunicação ativa na leitura e interpretação de situações problemas envolvendo figuras geométricas planas para crianças cegas. Para isso, a pesquisadora acompanhou dois estudantes cegos durante o período de um ano, realizando teste com adaptação das questões em escrita braille. Após o teste, apresentou suas atividades corrigidas e vivenciadas por meio da construção de uma maquete com a utilização de EVA. Outros materiais empregados para vivenciar a realidade foram um material dourado e o geoplano para apresentar conceitos de área e perímetro. A pesquisadora percebeu que uma das dificuldades em resolver problemas que envolvem a Geometria é a forma como as questões são elaboradas para o exame.

Santos (2018), em sua pesquisa Ensino de Geometria: construção de materiais didáticos manipuláveis com alunos surdos e ouvintes, teve o objetivo de observar os resultados por meio de uma sequência didática com estudantes surdos e ouvintes, com o auxílio de um material manipulável para o ensino da Geometria. Para isso, construíramse materiais manipuláveis para entender a fórmula do quadrado, retângulo, paralelogramo e triângulo, apresentando conceitos de área e suas propriedades. O pesquisador concluiu que o material didático manipulável auxilia o professor no ensino da Geometria para estudantes surdos e ouvintes.

Silva (2018) teve o objetivo de investigar professores de Matemática cegos e professores que ensinam Matemática para estudantes cegos ao desenvolver a pesquisa Ensino de Geometria para estudantes cegos: avaliação, análise e uso de um material manipulável por professores dos Anos Iniciais do Ensino Fundamental, identificando materiais manipuláveis destinados ao ensino de poliedros no ensino da Geometria. As professoras que ensinam estudantes cegos realizaram plano de aula com o auxílio de material manipulável, enquanto os professores cegos tiveram a oportunidade de participar 
da construção e manipulação do material manipulável, "pois além do conhecimento docente esses professores podem fazer críticas baseadas na experiência tátil que terão ao explorar o material" (SILVA, 2018, p. 58). Nos materiais manipuláveis, foram utilizados papel, guache, velcro, lã de crochê e papel-camurça, conferindo diferentes texturas e relevos específicos, podendo contribuir para o ensino da Geometria para estudantes cegos. A partir deles, apresentaram-se o nome dos polígonos, faces, arestas, vértices, planificação e comparação de figuras planas e espaciais.

Apresentada a síntese das pesquisas selecionadas, a próxima seção discute os resultados e análise desta pesquisa.

\section{Resultados e análise}

Quanto ao primeiro questionamento, sobre as deficiências e/ou transtornos abordados nessas pesquisas diante do contexto educacional, Arnoldo Junior (2010) realizou a pesquisa com dois estudantes surdos; Silva (2013) dedicou o processo de sua pesquisa para um único estudante com deficiência visual que "possui cegueira total, perdeu sua visão aos oito anos de idade" (p. 39); Silveira (2017) acompanhou dois estudantes com deficiência visual do $6^{\circ}$ ano do Ensino Fundamental que adquiriram cegueira congênita; Santos (2018) realizou a pesquisa com estudantes do $9^{\circ}$ ano do Ensino Fundamental, sendo dois surdos e oito ouvintes; e Silva (2018) informou que participaram de sua pesquisa seis professores e dois estudantes:

\footnotetext{
Dois professores brailistas atuantes na região metropolitana do Recife; 02 professores cegos, sendo: 01 professor cego brailista que trabalha com tecnologias digitais; um professor cego que atuou nos anos iniciais de escolas da rede municipal de Recife, atualmente trabalha com inclusão digital; dois professores que ensinam matemática e que têm estudantes cegos, ambos lecionam no $2^{\circ}$ ano do Ensino Fundamental da rede municipal de Paulista/PE, identificaremos as escolas como A e B; 02 estudantes cegos matriculados no $2^{\circ}$ ano do Ensino Fundamental da rede municipal de Paulista/PE (SILVEIRA, 2017, p. 55-56).
}

Percebeu-se que, durante as pesquisas, houve um equilíbrio nos resultados das deficiências, sendo que, em algumas, os pesquisadores realizaram suas práticas tanto com estudantes com deficiência quanto com estudantes sem deficiência indicada. Dessa forma, associa-se que a aprendizagem e a escola são para todos de forma igualitária, concordando com Mantoan (2003, p. 7-8) quando afirma "que as escolas sejam instituições abertas 
incondicionalmente a todos os alunos e, portanto, inclusivas". Nesse viés, verificaram-se indícios do Desenho Universal para Aprendizagem, pois se compreende que os autores procuraram formas para "entender como criar currículos que atendam às necessidades de todos os estudantes desde o primeiro momento" (SEBASTIÁN-HEREDERO, 2020, p. 733).

As pesquisas de Arnoldo Junior (2010), Silva (2013), Silveira (2017) e Silva (2018) citam que, entre seus participantes, estão estudantes com idades avançadas para o ano em que estavam e com dificuldades na aprendizagem e na utilização da Libras, sendo considerados pelos autores como barreiras comunicativas entre os estudantes e o professor. Nesse contexto, Mantoan (2003, p. 23) expressa a relevância de

instrumentos necessários à eliminação das barreiras que as pessoas com deficiência naturalmente têm para relacionar-se com o ambiente externo, como, por exemplo: ensino da Língua Brasileira de Sinais (Libras), do código braile, uso de recursos de informática, e outras ferramentas e linguagens que precisam estar disponíveis nas escolas ditas regulares.

A escola deve estar adaptada para receber os estudantes em diversos aspectos culturais e sociais, devendo os instrumentos auxiliar o entendimento e as comunicações entre estudantes e professores. A utilização da Libras e de outros instrumentos pode facilitar a barreira comunicativa para compreensão e interpretação da aprendizagem, sendo estratégias indicadas pelas diretrizes do Desenho Universal para Aprendizagem, contribuindo com professores para diminuir as dificuldades encontradas durante os processos de ensino e de aprendizagem. Tal movimento é considerado

\footnotetext{
uma expressão de referência geral para o desenvolvimento do DUA, que podem ajudar qualquer professor ou gestor que planeje unidades didáticas ou desenvolva currículos (objetivos, métodos, materiais e avaliações) para minimizar barreiras, assim como otimizar os níveis de desafios e ajudas (SEBASTIÁN-HEREDERO, 2020, p. 233).
}

Quanto às dificuldades específicas de aprendizagem que os estudantes apresentaram no ensino da Matemática e/ou da Geometria, terceiro questionamento desta pesquisa, Arnoldo Junior (2010) não identificou uma dificuldade específica, mas focou na leitura e na escrita, que poderia chegar à uma discalculia. Diante disso, o pesquisador comentou que a dificuldade não existe, "o que existe é uma barreira que vai sendo amenizada até ser eliminada, baseada no tempo e na posição de aprendizagem de cada 
aluno" (ARNOLDO JUNIOR, 2010, p. 111). Tal observação corrobora as diretrizes do Desenho Universal para Aprendizagem, que trazem que "os estudantes diferem nos modos como percebem e compreendem a informação que lhes é apresentada" (SEBASTIÁN-HEREDERO, 2020, p. 736).

Silva (2013, p. 12) identificou que, além da dificuldade no aprendizado da matéria, os deficientes visuais "acabam sofrendo também com o despreparo tanto das escolas quantos dos profissionais da área de Matemática". A dificuldade dos estudantes está relacionada, especificamente, a Geometria Espacial e Plana, sendo relatada a falta de recursos didáticos concretos para auxiliar nas aulas de Matemática. Para Silva (2013, p. 15), "o aluno com necessidades especiais deve ter o material adaptado de acordo com sua necessidade para poder acompanhar diariamente as aulas com os colegas". Pelo observado, a pesquisa apresentou um material didático adaptado somente para o estudante com deficiência, o que, de certa forma, não proporciona uma metodologia baseada no Desenho Universal para Aprendizagem, que, segundo Sebastián-Heredero (2020, p. 735), “considera a variabilidade/diversidade dos estudantes ao sugerir flexibilidade de objetivos, métodos, materiais e avaliações, permitindo aos educadores satisfazer carências diversas".

Ao utilizar um material de uso exclusivo para um estudante, não se consideram a diversidade e a variabilidade presentes na sala de aula, ocorrendo, muitas vezes, a segregação, visto que o estudante com material adaptado se "isola" dos demais para utilizar "seu" material didático. Mantoan (2003, p. 41) afirma que o professor que "explora os espaços educacionais com seus alunos, buscando perceber o que cada um deles consegue apreender do que está sendo estudado e como procedem ao avançar nessa exploração", pode contribuir para um processo educativo inclusivo, pois, ao buscar formas de ensinar, adaptando o cotidiano para avançar na compreensão e construção do conhecimento pelo estudante, garante atendimento a todos os envolvidos nesse processo, efetivando a inclusão.

Silveira (2017, p. 44) comenta que "as crianças cegas, durante o processo de orientação, podem sentir dificuldades espaciais com relação aos quatro tipos de orientações a partir da consciência de sua localização". Nesse sentido, "para a pessoa cega se movimentar de um ponto para outro é preciso não apenas ler ou seguir rotas, mas estar 
alerta, orientada em relação ao seu destino, construindo, mesmo involuntariamente, um mapa mental da mudança" (SILVEIRA, 2017, p. 45). A pesquisadora sugere a impressão e confecção de mapas e plantas táteis que possam facilitar o entendimento e a interpretação desses estudantes cegos, sanando as dificuldades espaciais durante o processo de construção do conhecimento.

A prática de Silveira (2017) utilizou o mesmo princípio de Silva (2013), ao desenvolver material exclusivo paro o estudante com deficiência. Apesar de não ser o sugerido pelas diretrizes do Desenho Universal para Aprendizagem, entende-se que "as opções para atingi-los são variadas e suficientemente fortes para proporcionar uma educação efetiva para todos os estudantes" (SEBASTIÁN-HEREDERO, 2020, p. 736), restando aos pesquisadores e professores fazer uso do material com todos os estudantes da sala.

Santos (2018) descreve que alguns dos estudantes ouvintes relataram pouca dificuldade de manusear o material didático manipulável, com 27 peças confeccionadas com papel de gramatura $430 \mathrm{~g}$, com vistas a fazer demonstrações algébricas das fórmulas de áreas, como quadrado, retângulo, entre outras. Os estudantes cegos consideraram uma atividade difícil, mas conseguiram assimilar o que foi proposto. Destaca-se que foi constatada a importância do trabalho em grupos, envolvendo a relação dos estudantes ouvintes, sem nenhuma deficiência, com os estudantes surdos, efetivando a inclusão social e a inter-relação. Veem-se aqui algumas das diretrizes do Desenho Universal para Aprendizagem, como "criar grupos de colaboração com objetivos, funções e responsabilidades claras [...] oferecer expectativas para o trabalho em grupo" (SEBASTIÁN-HEREDERO, 2020, p. 764).

Para Silva (2018, p. 27), “é necessário que em função das limitações que decorrem da deficiência que afeta a percepção visual sejam disponibilizados recursos que tendam a suprir ou minimizar dificuldades na compreensão de diversos conteúdos permeados por apelos visuais". A autora indica que a dificuldade dos estudantes está ligada aos sólidos geométricos, não podendo "discernir sobre qual sólido precisaria ser montado" (SILVA, 2018, p. 86). O material manipulado utilizado representava poliedros regulares, tendo sido construído com papel, guache, lã de crochê, papel-camurça e velcro, para explorar as planificações, arestas, vértices e faces, conteúdos do ensino da geometria. O estudante cego sugeriu contato com os sólidos prontos para auxiliar em sua montagem, uma vez 
que foi entregue aos estudantes a planificação dos sólidos e eles precisaram desenvolver o processo de construção do seu conhecimento. Mantoan (2003, p. 16) explica que a “inclusão implica uma mudança de perspectiva educacional, pois não atinge apenas alunos com deficiência e os que apresentam dificuldades de aprender, mas todos os demais, para que obtenham sucesso na corrente educativa geral".

Buscando verificar o conceito de Educação Inclusiva adotado pelos pesquisadores, destacam-se as seguintes informações: Silva (2013, p. 71) considera a "Educação Inclusiva uma educação onde todos os alunos têm o acesso aos assuntos trabalhados em sala de aula, seja qual for a deficiência"; Silva (2018, p. 14) afirma que “o acesso à Educação também é direito da pessoa com deficiência. Nesse sentido, os sistemas de ensino devem assegurar uma Educação Inclusiva para essas pessoas em todos os níveis de escolarização”. Arnoldo Junior (2010), Silveira (2017) e Santos (2018) entendem Educação Inclusiva como aquela que oferece acesso a todos.

As pesquisas evidenciam que o entendimento do estudante está na barreira comunicativa, como a ausência de profissional adequado para realizar atendimento educacional especializado e mesmo tradutor e intérprete de Libras. Ainda, destacam a política governamental, que não disponibiliza o curso básico aos professores para o entendimento desses estudantes, como, por exemplo, aqueles com surdez. Cabe ressaltar que foi observado nessas pesquisas que os professores procuram construir algum material que possa resolver o problema naquele momento de seu planejamento educacional.

\section{Considerações}

Este artigo buscou revelar se as pesquisas com temática sobre práticas de ensino inclusivas em Geometria na Educação Matemática trazem indícios sobre o Desenho Universal para Aprendizagem. Para tanto, desenvolveu-se uma pesquisa qualitativa, por meio de revisão bibliográfica, tendo sido selecionadas cinco pesquisas nas bases de dados BDTD, SciELO e Catálogo de Teses e Dissertações da CAPES. A partir da análise dessas pesquisas selecionadas, percebeu-se que os pesquisadores, ou grande parte dos professores, acabam adaptando atividades práticas para que os estudantes com deficiências possam obter a garantia do ensino e aprendizagem. A respeito, Mantoan (2003, p. 22) comenta que "toda escola deve atender aos princípios constitucionais, não 
podendo excluir nenhuma pessoa em razão de sua origem, raça, sexo, cor, idade ou deficiência”.

Identificaram-se alguns problemas de aprendizagem com o ensino da Matemática, para os quais foram apresentados materiais manipuláveis, que atenderam especificamente a determinado estudante com deficiência. Assim, pode-se dizer que os materiais criados pelos pesquisadores não contemplaram os sete princípios do Desenho Universal; Gabrilli (2007, p. 5) expressa que "este conceito que tem como objetivo definir projetos de produtos e ambientes que contemplem toda a diversidade humana: desde as crianças, adultos altos e baixos, anões, idosos, gestantes, obesos, pessoas com deficiência ou com mobilidade reduzida".

Por outro lado, o professor pode explorar diversas formas de ensinar para que o estudante construa/desenvolva sua aprendizagem de forma efetiva. $\mathrm{O}$ estudante com deficiência pode construir seus conhecimentos por meio das práticas pedagógicas elaboradas pelo professor, que deve lembrar que é responsável pelos processos de ensino e de aprendizagem de cada estudante, com deficiência ou não. Destaca-se que, por vezes, o professor não tem diariamente, por exemplo, um tradutor e intérprete de Libras auxiliando em suas explicações, apesar de isso ser garantido em lei. Assim, é necessária uma forma de comunicação e representação para que o estudante tenha sua aprendizagem garantida, conforme diretrizes do Desenho Universal para Aprendizagem.

Com esta discussão, fica evidente que existem práticas na Educação Inclusiva que normalmente não contemplam todos os estudantes; sendo assim, elas são adaptadas para que, em certos momentos, sejam utilizadas para resolver um problema específico de aprendizagem, diante da dificuldade de cada estudante. Na maioria das pesquisas investigadas, percebeu-se que os materiais didáticos ou manipuláveis construídos, apesar de serem apresentados a todos da classe, geralmente foram utilizados apenas pelos estudantes com deficiência. Assim, a despeito de as pesquisas trazerem isoladamente algumas diretrizes do Desenho Universal para Aprendizagem, sua essência, que é a universalidade da educação, tornando o trabalho colaborativo, com socialização dos conhecimentos, parece ainda não ser o foco.

As discussões sobre o Desenho Universal para Aprendizagem são recentes nas pesquisas brasileiras; como observado, nenhum dos trabalhos mencionam seus princípios 
e diretrizes metodológicas. No entanto, tem-se nele uma concepção de trabalho pedagógico em sala de aula que não segrega o grupo, mas que efetiva a real inclusão, com estudantes utilizando os mesmos materiais didáticos, trabalhando em propostas colaborativas, sendo atores de sua aprendizagem.

Conclui-se que esse estudo possibilita reflexões a respeito da utilização do DUA na elaboração de atividades e planejamento no ensino de Matemática, assim como nos demais, visando à inclusão para todos os estudantes com/sem deficiência podendo contribuir com a aprendizagem no ensino da Matemática. Uma vez que se compreende que o Desenho Universal para aprendizagem possibilita com suas diretrizes metodológicas proporcionar o ensinar a todos.

Posto isso, pode-se dizer, a partir das análises realizadas, que a Educação Inclusiva na Matemática requer estratégias de ensino que atendam a todos os estudantes, além de adequação de estrutura física e metodológica por parte dos professores. Também se destaca que os pesquisadores enfrentaram algumas dificuldades para que fossem realizadas as pesquisas, mas se faz necessário ter um olhar diferenciado na construção dos materiais manipuláveis para atender a todos os estudantes, com e sem deficiência, tornando as propostas realmente inclusivas, sendo assim, destaca-se a importância de todos os professores conhecerem o DUA e o integrarem sempre que necessário em suas práticas didáticas, garantindo assim o direito a aprendizagem a todos os estudantes.

\section{Referências}

AROLDO JUNIOR, Henrique Aroldo. Estudo do desenvolvimento do pensamento geométrico por alunos surdos por meio do multiplano do Ensino Fundamental. 2010. 292f. Dissertação (Mestrado em Educação em Ciências e Matemática) — Escola Politécnica. Pontifícia Universidade Católica do Rio Grande do Sul. Porto Alegre.

BRASIL. Ministério da Educação. Secretaria de Educação Especial. Política Nacional de Educação Especial na Perspectiva da Educação Inclusiva. Brasília: MEC/SEE, 2008.

BRASIL. Decreto $n$. 6.949, de 25 de agosto de 2009. Promulga a Convenção Internacional sobre os Direitos das Pessoas com Deficiência e seu Protocolo Facultativo, assinados em Nova York, em 30 de março de 2007. Brasília: Diário Oficial da União, 26 ago. 2009.

BRASIL. Lei $n^{o} 13.146$, de 6 de julho de 2015. Institui a lei brasileira de inclusão da pessoa com deficiência (estatuto da pessoa com deficiência). Brasília: Diário Oficial da União, 7 jul. 2015. 
BRASIL. Lei $n^{\circ}$. 9.394, de 20 de dezembro de 1996. Estabelece as diretrizes e bases da educação nacional. Brasília: Diário Oficial da União, 23 dez. 1996.

BRASIL. Ministério da Educação. Declaração de Salamanca: sobre princípios, políticas e práticas na área das necessidades educativas especiais. Brasília: MEC/UNESCO, 1994.

BRASIL. Ministério da Educação. Secretaria de Educação Básica. Base Nacional Comum Curricular: Educação Infantil e Ensino Fundamental. Brasília: MEC/SEB, 2017.

CAST — Center for Applied Special Technology. Until learning has no limits. Disponível em http://www.cast.org; acesso em 03 jan. 2021, às 16h30.

GABRILLI, Mara. Guia Desenho Universal: um conceito para todos. Brasília: Manual Ilustrativo, 2007. Disponível em https://www.maragabrilli.com.br/wpcontent/uploads/2016/01/universal_web-1.pdf; acesso em 29 nov. 2020, às 15h15.

GÓES, Anderson Roges Teixeira; GÓES, Heliza Colaço. Ensino da Matemática: concepções, metodologias, tendências e organização do trabalho pedagógico. Curitiba: InterSaberes, 2015.

HOUAISS, Antônio; VILLAR, Mauro de Salles. Dicionário Houaiss da Língua Portuguesa. Rio de Janeiro: Objetiva, 2009.

LORENZATO, Sergio. Por que não ensinar Geometria? Educação Matemática em Revista, Brasília, v. 3, n. 4, p. 3-13, jan./jun. 1995.

MANTOAN, Maria Teresa Eglér. Inclusão escolar: O que é? Por quê? Como fazer? São Paulo: Moderna, 2003.

MORAES, Louise. A educação especial no contexto do Plano Nacional de Educação. Brasília: INEP, 2017.

PARANÁ. Secretária da Família e Desenvolvimento Social. Conhecendo a pessoa com Deficiência. Curitiba: SEDS, 2018.

SANTOS, Lijecson Souza dos. Ensino de Geometria: construção de materiais didáticos manipuláveis com alunos surdos e ouvintes. 2018. 190f. Dissertação (Mestrado em Ensino de Ciências e Educação Matemática) - Centro de Ciências e Tecnologia. Universidade Estadual da Paraíba. Campina Grande.

SEBASTIÁN-HEREDERO, Eladio. Diretrizes para o Desenho Universal para a Aprendizagem (DUA). Revista Brasileira de Educação Especial, Bauru, v. 26, n. 4, p. 733-768, out./dez. 2020.

SILVA, Davi Cezar da. O ensino da Geometria para alunos com deficiência visual. 2013. 79f. Dissertação (Mestrado em Ensino de Física e de Matemática) — Universidade Franciscana. Santa Maria.

SILVA, Mayra Darly da. Ensino de Geometria para estudantes cegos: avaliação, análise e uso de um material manipulável por professores dos Anos Iniciais do Ensino Fundamental. 2018. 186f. Dissertação (Mestrado em Educação Matemática e 
Tecnológica) — Centro de Educação. Universidade Federal de Pernambuco. Recife.

SILVEIRA, Denize Francisca Oliveira da. Comunicação ativa na leitura e interpretação de situações problemas envolvendo figuras geométricas planas para crianças cegas. 2017. 131f. Dissertação (Mestrado em Educação) — Faculdade de Educação. Universidade Federal do Ceará. Fortaleza.

TREVISOL NETO, Orestes. Métodos e técnicas de pesquisas. Chapecó: Argos, 2017.

VALENTE, Tamara da Silveira. Da inclusão ao direito à inclusão. In: GUÉRIOS, Ettiène; STOLZ, Tania. (Org.). Educação em direitos humanos: qual sentido? Ijuí: Unijuí, 2015, p. 169-201. 